\title{
Arrowhead Injury of Central Nervous System: Three Rare Cases from Rural India
}

\author{
Viraat Harsh ${ }^{1 *}$ Hemant Alda ${ }^{*} \quad$ Shashwat Singh ${ }^{1}$ \\ ${ }^{1}$ Department of Neurosurgery, Rajendra Institute of Medical \\ Sciences, Ranchi, Jharkhand, India \\ 2 Department of Neurosurgery, Anugrah Narayan Magadh Medical \\ College, Gaya, Bihar, India
}

\author{
Jayendra Kumar ${ }^{2} \quad$ Chandra B. Sahay $^{1} \quad$ Anil Kumar $^{1}$
}

Indian J Neurotrauma 2021;18:138-141.

\author{
Address for correspondence Anil Kumar, MBBS, MS, MCh, \\ Department of Neurosurgery, Rajendra Institute of Medical \\ Sciences, Ranchi 834009, Jharkhand, India \\ (e-mail: dr.anilkumarranchi@gmail.com).
}

\begin{abstract}
Keywords

- arrow injury

- penetrating injury

- missile injury

A penetrating central nervous system (CNS) injury on account of an arrowhead is a rarity in the modern era. When managing such cases surgically, special care is taken to prevent injury to the neurovascular structures lying in the vicinity of the wound. Fired arrows are categorized as low-velocity missiles, but the size, shape and aerodynamic stability of the missile are also important factors in establishing the complexity of the wound. We present three such cases of penetrating injury of the CNS by fired arrows, two injuring the head and the third injuring the spinal cord. The arrowheads were successfully retrieved without any complications. Salient features to be taken care of while managing such patients have also been also discussed.
\end{abstract}

\section{Introduction}

Since the advent of modern era weapons and artillery, penetrating injuries by old world missiles, such as arrows, lances and spears have only been rarely reported in the medical literature, especially in the Western world. Few cases of arrowhead injuries have however been reported from the Indian subcontinent, especially from the tribal areas. Very few of these cases describe central nervous system (CNS) injuries caused by fired arrows. Arrowhead injuries depend on the type of bow and arrow used. An important determinant of severity of injury caused by an arrow, as of any other missile injury, is the velocity of the missile. The average velocity of a bow-fired arrow is approximately 60 to $90 \mathrm{~m} / \mathrm{s}^{1}$ The extent of injury and soft and bony tissue destruction also depend on the size, shape and aerodynamic stability of the arrow. We report three cases of arrowhead injury of the head and spine and discuss their management.

\section{Case 1}

A 65-year-old female patient presented to our emergency room following penetrating trauma to her head by an arrow fired by her psychotic son. She complained of pain at the

* These authors contributed equally to this work.

published online

September 23, 2020
DOI https://doi.org/

$10.1055 / \mathrm{s}-0040-1716433$ ISSN 0973-0508. site of injury and nasal bleeding. There was no history of loss of consciousness, vomiting or convulsions. On initial examination, she was conscious with a Glasgow coma scale (GCS) score of E4V5M6 and stable vitals. An arrowhead was impacted on the forehead $5 \mathrm{~cm}$ above the nasion, lateral to the midline on the right, with the direction of impact being downward, laterally and toward the posterior (-Fig. 1). Ophthalmological examination and complete neurological assessment were unremarkable. An emergency bedside X-ray of the skull revealed the orientation and trajectory of the foreign body sparing the brain parenchyma (-Fig. 2), which was later confirmed on a CT scan of the head. Surgery was offered to the patient and her family, to which they agreed. A regional craniectomy was performed around the site of penetration to permit the arrow free from the bone and facilitate its gentle extraction in the line of its trajectory, following which the wound was inspected under direct vision for any bleeding or cerebrospinal fluid (CSF) leak. Extended craniectomy revealed a breached dura. Duroplasty was performed with autologous tensor fascia lata graft, and the wound was closed in layers after securing hemostasis. The postoperative period was uneventful. The patient received broad-spectrum antibiotics and was discharged on the ninth day postoperatively. At 6 months follow-up after surgery, the patient was asymptomatic and clinically normal.

\section{(c) 2020. Neurotrauma Society of India.}

This is an open access article published by Thieme under the terms of the Creative Commons Attribution-NonDerivative-NonCommercial-License, permitting copying and reproduction so long as the original work is given appropriate credit. Contents may not be used for commercial purposes, or adapted, remixed, transformed or built upon. (https://creativecommons.org/licenses/by-nc-nd/4.0/).

Thieme Medical and Scientific Publishers Pvt. Ltd. A-12, 2nd Floor, Sector 2, Noida-201301 UP, India 


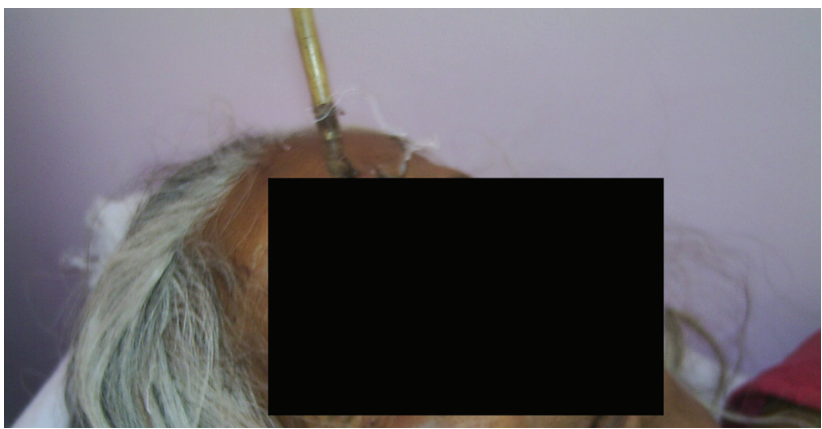

Fig. 1 Figure showing arrow injury of the forehead.
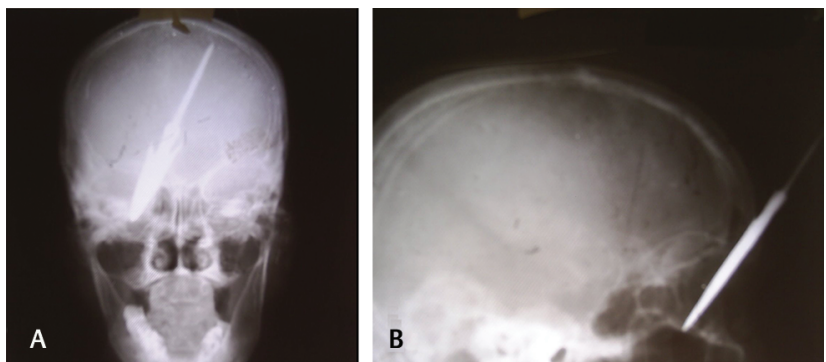

Fig. 2 X-rays showing arrow injury and its trajectory in the head. (A) AP view. (B) Lateral view.

\section{Case 2}

A 70-year-old male patient came to our emergency room following penetrating trauma to the upper back by an arrow that was fired by his relative over a family dispute. On examination, the patient was conscious (GCS E4V5M6) with stable vitals. An arrowhead was seen impacted on the upper back, $3 \mathrm{~cm}$ from the midline, on the right side, and at the level of D4-D5vertebrae, with the direction of the impact being medially and anteriorly toward the cord. On examination, power in both lower limbs was Grade 0/5, tone was increased, all reflexes in lower limb were exaggerated, and plantar bilaterally upgoing. Sensation below the xiphisternum was absent bilaterally. Position and vibration sense in lower limbs were absent. Bladder and bowel incontinence were present. CT scan of thoracic spine ( $\mathbf{- F i g}$. 3) demonstrated the trajectory of foreign body and the extent of trauma to the spinal cord. With consent of the patient and his family members,
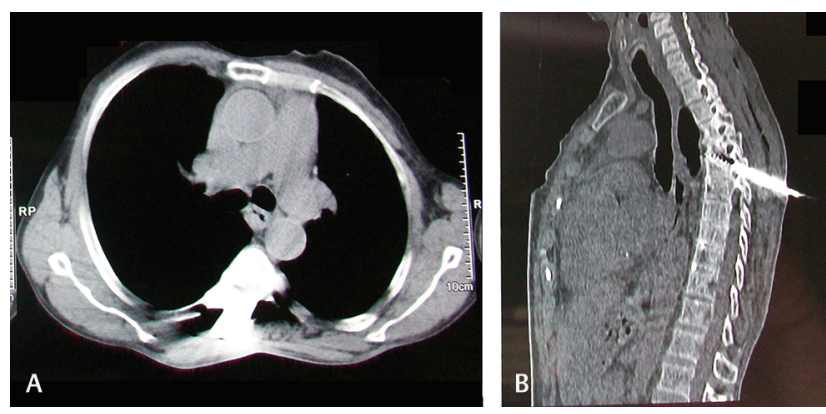

Fig. 3 CT scan showing arrow injury and its trajectory in the back. (A) Axial view. (B) Sagittal view.

he was taken up for immediate removal of the offending arrow. Following a midline skin incision at the back from D2D6 ( Fig. 4A), paraspinal muscles were separated and the arrowhead was visualized to be impacting the bony lamina at the level of D4-D5, subsequent to which laminectomy was performed to make it free from the bone for gentle extraction of the arrowhead in its line of trajectory (-Fig. 4B). The wound was inspected under direct vision. Dura and underlying spinal cord were found to be damaged with no active bleeding; however, CSF was seen leaking through the compromised dura. After thorough irrigation with normal saline, the dura was repaired in water-tight fashion and the wound was closed in layers. The postoperative period was uncomplicated, and the patient was discharged with Foley's catheter in situ on the 11 th postoperative day with Grade $1 / 5$ power in both lower limbs and hyperesthesia. Follow-up after 6 months showed improved power to Grade $3 / 5$ in both lower limbs, but bladder and bowel incontinence persisted.

\section{Case 3}

A 14-year-old female came to our emergency room following penetrating trauma by an arrow fired during play (-Fig. 5A). She was conscious (GCS E4V5M6). There was no history of loss of consciousness or seizures. The patient, however, had vomited twice after the injury. On examination, the arrow was seen penetrating the skull over the right frontal region. CT scan of the brain showed that the arrow was in the right frontal bone not piercing the dura ( $\mathbf{F}$ Fig. 5B). The brain parenchyma was normal. The patient was taken to the
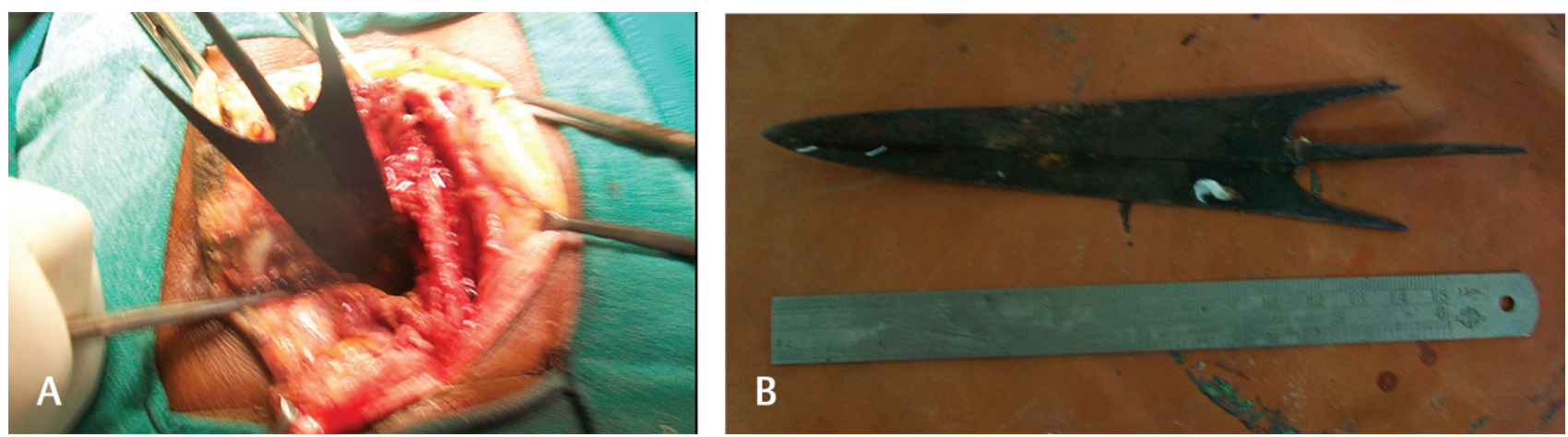

Fig. 4 (A) Figure showing intraoperative photograph of spine arrow injury. (B) Figure showing extracted arrowhead. 

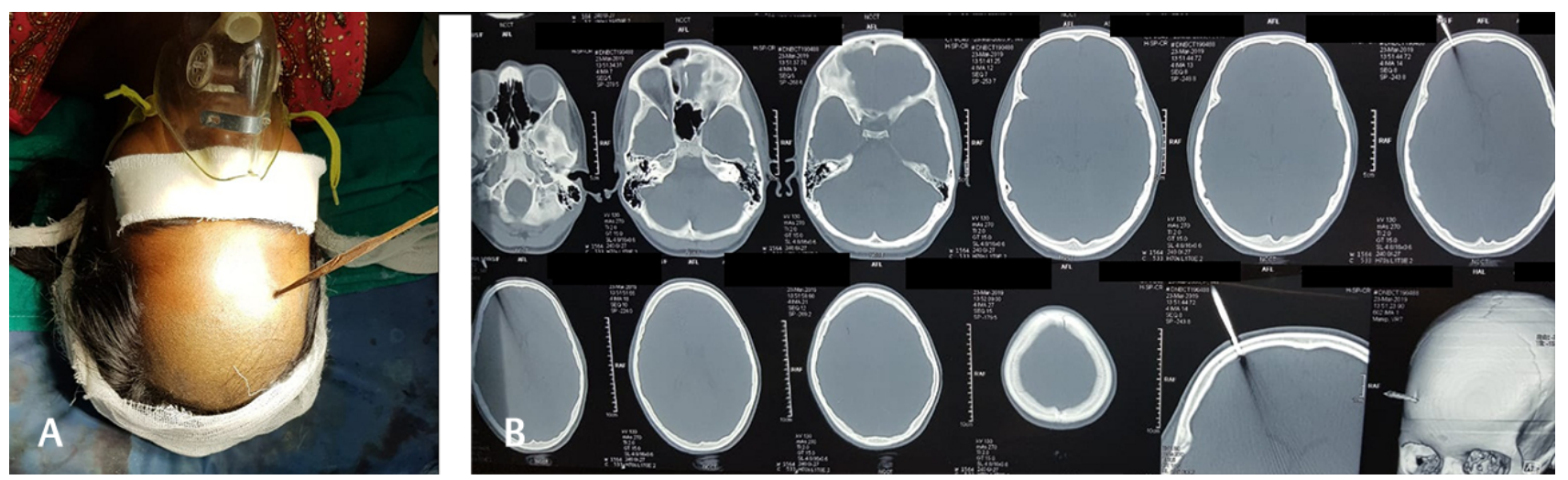

Fig. 5 (A) Figure showing photograph of arrowhead injury over the forehead. (B) CT scan showing arrow injury piercing the right frontal bone.

operating room for removal of the arrow. Under local anesthesia and sedation, the arrowhead was pulled out through a narrow craniectomy. The wound was cleaned with hydrogen peroxide and betadine, and the skin was closed in layers. The postoperative period was uneventful, and the patient was discharged the following day. The patient was conscious at the time of discharge and without any neurodeficit. The patient came for follow-up for 6 months.

\section{Discussion}

Arrow injuries are an extinct mode of injury in the Western world but off and on it is encountered in the tribal areas of India, sometimes unintentional while hunting, and quite often charged on purpose, but also merely while playing, as was seen in one of our cases. A rare case of suicide by arrowhead has also been reported. ${ }^{2}$ Most of the arrow injuries involve the thorax and abdomen. ${ }^{3}$ Arrow injuries to head are rare and mostly involve the face. ${ }^{1,4}$ However, those involving the CNS are fairly uncommon, although a few cases have been reported..$^{5-7}$

The mechanism of injury caused by fired arrow is similar to injuries caused by low-velocity missiles. Arrows have a considerable penetrating capacity in soft tissue and flat bones. Arrow injuries are usually less destructive than those caused by high-velocity missiles because of their lower velocity and energy. Barbed arrows are an exception because of the risk of extensive damage to major structures when retrieved. ${ }^{8}$ An arrow injury to the brain may be considered intermediate between a gunshot wound and stab wound. Size, shape, aerodynamic stability, and velocity of the missile are important factors which decide the severity of injuries by arrows. The size of the arrow in the second case was $17 \mathrm{~cm}$ and it had

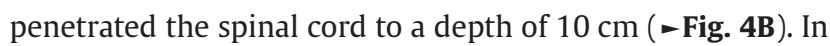
the first case, $6 \mathrm{~cm}$ of the arrowhead had penetrated the skin. In the third case, the arrow had penetrated the frontal bone but had not crossed the inner table.

Radiography of the skull is helpful in demonstrating the intracranial course of metallic materials, but the radiodensity of wood is nearly the same as that of soft tissue and the brain, so it can be difficult to detect. ${ }^{9} \mathrm{CT}$ is valuable for detecting wooden foreign bodies as hypodense mass. ${ }^{10}$ Wooden bodies also appear hypodense on T1- and T2-weighted MR imaging. ${ }^{11}$ However, it has also been observed that the CT and MR imaging properties of a wooden foreign body can change in vivo after a long period of intraparenchymal retention. ${ }^{12}$ However, in most cases, a CT scan would provide valuable information about the course of injury and the depth of penetration of the arrowhead. There is a report about an unusual head trauma in an adult due to an accidental pressure cooker explosion, where the patient did not have any focal neurological deficit but had experienced debilitating headache and multiple episodes of vomiting. ${ }^{13}$ A pneumocephalus was seen on $\mathrm{CT}$, and the consequent raised intracranial tension was deemed responsible for the presenting symptoms, which subsided over 2 days along with the resolution of the air pocket as confirmed by a repeat CT. Such complications might also accompany a penetrating injury of the brain, and their presence on a CT could provide an answer for the accompanying symptoms of headache and/ or vomiting.

CT angiography of brain helps to evaluate the extent of cerebrovascular trauma. Injuries such as arterial dissection, pseudoaneurysm, arterial or venous thrombosis and arteriovenous fistula can be successfully identified and repaired. ${ }^{14}$ If vascular injury is suspected, a CT angiography will be life-saving. An arrow should never be removed from a patient, irrespective of stability, unless injury to major vessels has been ruled out. ${ }^{15}$ It may be emphasized that arrow removal is not suggested unless in an emergency trauma care facility. Prompt extraction is advised only under direct vision, keeping in mind the tamponade effect which may be encountered by the major vessels that may then subsequently bleed.

Management of arrow injury to the CNS should aim at prevention of infection, exploration for potential dural tears, and subsequent CSF loss, leading to intracranial hypotension and minimizing the secondary injuries that may be caused by the missile. The patient should be immobilized well before and during the transfer to a hospital, especially if the arrow is unstable. Another important strategy is early extraction of arrowhead to minimize neurological deficits but should be removed only at a center where adequate facilities to control hemorrhage are available. ${ }^{6}$ Arrow injuries are reported to have $1.4 \%$ infection rate. ${ }^{3}$ Broad-spectrum antibiotic coverage is instituted to prevent infection. 
Another complication of penetrating brain injury is the occurrence of posttraumatic seizures. The incidence of posttraumatic seizure is higher in penetrating brain injuries than with closed brain injuries and occurs in over $50 \%$ penetrating trauma cases over a follow-up period of 15 years. ${ }^{16}$ Hence, patients must be informed about the possibility, and a proper plan for regular follow-up should be discussed with them.

Speech problems may also occur as a part of penetrating brain injuries. There was a case which consisted of a man presenting with an arrow lying in the brain at the left parieto-occipital region through the right frontal lobe accompanied with intraparenchymal hematoma ${ }^{7}$. He had motor aphasia at presentation which persisted after the surgical removal of the arrow. Once intracranial vascular injuries were ruled out by MR angiography, he was discharged on the second week of the event with severe motor aphasia. With the help of intensive speech therapy, he had begun to talk in the first month by using simple words. So, a consultation with a speech therapist can be considered to treat any difficulty with speech the patient might experience postoperatively.

Pediatric age group patients are more prone to secondary brain insult, requiring better attention and timely intervention. They are more susceptible to the secondary insult of brain from low-oxygen saturation, fluid imbalances, electrolyte disturbances, fever, and seizures requiring special care. ${ }^{17}$ Factors affecting the good outcome are amount of contamination, presence of dural breach, trauma-surgery time gap, quality of wound debridement, and appropriate and timely antibiotic and antiepileptic medication. ${ }^{18-20}$

\section{Authors' Contributions}

V.H. and J.K. conceptualized the article. V.H., S.S., H.A., and J.K. gathered the data. All the authors revised the article and approved the final draft of the article that was submitted. CB.S. and A.K. provided guidance toward the completion of the article.

\section{Funding}

None.

\section{Conflict of Interest}

None declared.

\section{References}

1 O'Neill OR, Gilliland G, Delashaw JB, Purtzer TJ. Transorbital penetrating head injury with a hunting arrow: case report. Surg Neurol 1994;42(6):494-497
2 Řehulka H, Čechová E, Mottlová J, Valenta M, Mareška Z. [Fatal head injury caused by a crossbow arrow with unusually preserved posttraumatic volitional activity - case report]. Soud Lek 2016;61(1):2-4

3 Madhok BM, Roy DD, Yeluri S. Penetrating arrow injuries in Western India. Injury 2005;36(9):1045-1050

4 Jha AK, Kumar J, Harsh V, Kumar A. Penetrating injury of the posterior cranial fossa by a stone. Neurol India 2016;64(5): 1081-1082

5 Paramhans D, Shukla S, Batra A, Mathur RK. Successful removal of an impacted metallic arrowhead penetrating up to the brainstem. J Emerg Trauma Shock 2010;3(3):303

6 Geissinger G, Magid GA, McMahon RC. Arrow trauma to cervical spine. WMJ 2009;108(4):197-199

7 Kurt G, Börcek AO, Kardeş O, Aydincak O, Ceviker N. Transcranial arrow injury: a case report. Ulus Travma Acil Cerrahi Derg 2007; 13(3):241-243

8 Jacob OJ. Penetrating thoracoabdominal injuries with arrows: experience with 63 patients. Aust N Z J Surg 1995;65(6): 394-397

9 Ginsberg LE, Williams DW, III, Mathews VP. CT in penetrating craniocervical injury by wooden foreign bodies: reminder of a pitfall. AJNR Am J Neuroradiol 1993;14(4):892-895

10 Hansen JE, Gudeman SK, Holgate RC, Saunders RA. Penetrating intracranial wood wounds: clinical limitations of computerized tomography. J Neurosurg 1988;68(5):752-756

11 Ho VT, McGuckin JF Jr, Smergel EM. Intraorbital wooden foreign body: CT and MR appearance. AJNR Am J Neuroradiol 1996;17(1):134-136

12 Ishikawa E, Meguro K, Yanaka K, et al. Intracerebellar penetrating injury and abscess due to a wooden foreign body-case report. Neurol Med Chir (Tokyo) 2000;40(9):458-462

13 Kumar M, Harsh V, Jha S, Prakash A, Kumar A, Sahay CB. An unusual case of head injury by pressure cooker explosion. Int J Med Sci Innovat Res 2018;3(2):152-154

14 Bula WI, Loe DJ. Trauma to the cerebrovascular system. Neuroimaging Clin N Am 1996;6:607-624

15 Peloponissios N, Halkic N, Moeschler O, Schnyder P, Vuilleumier H. Penetrating thoracic trauma in arrow injuries. Ann Thorac Surg 2001;71(3):1019-1021

16 Temkin NR, Dikmen SS, Winnn HR. Post traumatic seizures. Neurosurg Clin N Am 1991;2:425-435

17 Kumar J, Prakash A, Harsh V, Kumar A. Elevated fracture of skull in pediatric age group: A series of five patients with review of literature. Asian J Neurosurg 2016;11(1):75

18 Harsh V, Prakash A, Gupta U, Kumar J, Kumar A. Depressed fracture of the skull - an institutional experience of 453 patients. Asian J Neurosurg 2018; 13:222-6

19 Harsh V, Vohra V, Kumar P, Kumar J, Sahay CB, Kumar A. Elevated skull fractures- too rare to care for, yet too common to ignore. Asian J Neurosurg 2019; 14:237-9.

20 Harsh V, Besra SK, Kumar J, Kumar A. A curious case of spontaneously resolving closed 'jigsaw' depressed skull fracture in an adolescent. Asian J Neurosurg 2016; 11:109-10 